\title{
Public Policy or Government Programs? Are a Contribution to the Inclusion in Chile?
}

\author{
Jose Manuel Salum Tome ${ }^{1, *}$ \\ ${ }^{1}$ Departamento De Educacion, Universidad Catolica De Temuco, Temuco, Chile \\ *Correspondence: Departamento De Educacion, Universidad Catolica De Temuco, Temuco, Chile. Tel: \\ 56-9-3251-0172. E-mail: josesalum@gmail.com
}

Received: July 8, 2020

Accepted: August 18, $2020 \quad$ Online Published: October 14, 2020

doi:10.5430/wje.v10n5p80

URL: https://doi.org/10.5430/wje.v10n5p80

\begin{abstract}
Given the importance of Public Policies for social transformation, the document explains why and under what circumstances they constitute a decisive factor to promote or inhibit social transformation. A policy is a purposeful, intentional, planned behavior, not just reactive, casual. It is set in motion with the decision to achieve certain objectives through certain means: it is an action with meaning. It is a process, a course of action that involves a whole complex set of decisions and operators.Politics is also a public communication activity. Hence, the purpose of this article is s be a guide in the understanding and analysis of what is meant by Public Policies, as well as contributing to the understanding of the mechanisms for their design and elaboration. That they have a clear and simple idea of what Public Policies are in a generalized context and the steps that must be carried out to implement them.
\end{abstract}

Keywords: public policies, quality, social transformation

\section{Introduction}

The great task is to be a guide in the understanding and analysis of what the Public Policies mean, as well as to contribute to the understanding of their design and elaboration mechanisms. That they have a clear and simple idea of what Public Policies are in a generalized context and the steps that must be carried out to implement them.

Given the importance of Public Policies for social transformation, the document explains why and under what circumstances they constitute a decisive factor to promote or inhibit social transformation.

Educational policies are those public policies that respond, to some extent, to social requirements in the sectoral sphere of education. The definition of public policies, however, has different approaches, constantly evolving (Lahera, 2008; Espinoza, 2009). This evolution is linked to changes in our social, cultural, political, economic and institutional environment. Thus, while in the last century decision-making was exclusively state-based, with its power to create, structure and modify the cycle of public policies, today the participation of various actors, the creation of consensus and legitimacy in Public affairs have become unavoidable for governance in any territory.

From this perspective, conceptually it can be said that public policies "correspond to courses of action and information flows related to a democratically defined public objective; those that are developed by the public sector and, frequently, with the participation of the community and the private sector" (Lahera, 2008 p. 16). It is, in general, a set of interrelated options and decisions that implies the establishment of objectives and the definition of the means to achieve them, in response to policy demands ${ }^{1}$ (Kraft and Furlong, 2004; Fischer et al., 2007; Espinoza, 2009). From this perspective, public policies have to do with both actions and omissions. On the one hand, they involve a task to deal with problems on which actions at the public level are demanded and, on the other hand, they can be reduced to decisions of simply "doing nothing" in relation to some aspect or social problem (Kraft and Furlong, 2004; Fischer et al. 2007).

In this sense, public policies are instruments of governance that shape politics, assigning winners and losers between citizens and interest groups, which usually affects the policy cycle, participation and future demands (May \& Jochim, 2013). Thus, and since they serve both substantive and political commitments, public policies are, finally, a key component of the policy itself (May \& Jochim, 2013). 
Politics and public policies are different entities, but they influence each other. Both are sought in the opacity of the political system. Both politics and public policies have to do with social power. But while politics is a broad concept, relative to power in general, public policies correspond to specific solutions of how to manage public affairs. The English language clearly reflects this distinction between politics and policies.

Public policies are a common factor in government and opposition policy and decisions. Thus, politics can be analyzed as the search to establish public policies on certain subjects, or to influence them. In turn, a fundamental part of the government's work refers to the design, management and evaluation of public policies.

The objective of politicians - conservatives as well as radicals, idealists or motivated by self-interest is to get to establish public policies of their choice, or block those that are inconvenient. In any government alliance, those who confine themselves to the theses and do not seek its concretion in policies confuse their role.

Politics in its broadest sense tends to shape both public policy proposals and those that materialize. Who wants the government wants public policies. Therefore, governments are instruments for the realization of public policies. Rather than looking at the ordering of public sector activities, as given by your organization, it should be seen as an instrument for the realization of public policies. Just as the main achievement of a private company is not its organization chart, but its profits, what is important in government is its results, rather than its structure.

From what has already been said, public policies are useful for studying various aspects of politics, such as the discussion of the public agenda throughout society, the elections between candidates and their programs, the activities of the government, the activities of the opposition, the effort s analytical on these issues. In this way, this document aims to provide a panoramic vision of Chilean education between 2004 and 2016, considering the design and implementation of the profound reforms carried out during the second government of President Bachelet. For its study we will make the following division: policy analysis (search for the best Public Policy in terms of efficiency and equity) and the study of policy-making (policy-making study), positively guiding to describe, classify and explain the decision pattern and operation with which a given administrative political system or a particular government in Public Policies proceeds. Each of these parts leads to a deeper understanding of this topic, thus generating a further complementary idea.

\subsection{Que Mean by a Good Policy Public}

A public policy of excellence corresponds to those courses of action and information flows related to a democratically defined political objective; those that are developed by the public sector and, frequently, with the participation of the community and the private sector. A quality public policy will include guidelines or content, instruments or mechanisms, institutional definitions or modifications, and the forecast of its results, (Gómez, R., 2012)

The main thing is the idea, the point of view, or the objective from which to propose or analyze norms or provisions. Thus it is possible to consider one norm or decision or several (such as the "program" of the United States). The expression "policy space" has also been used to denote a set of policies so interrelated that useful analytical descriptions or statements of them cannot be made without taking into account the other elements of the set.

Public policies of excellence include the political aspect as its origin, objective, justification or public explanation. If public policies are not framed in a broad process of participation, this may bias public actors: specialists towards technocracy and communicators or surveyors towards immediate populism (Arellano, J. P., 2001)

An alternative to the inclusion of political considerations in public policies is the simple aggregation of specialists on some issues, or of communication supports - including the use of wedges and surveys to traditional government activities. From the most instrumental point of view, it must be remembered that public policies necessarily represent some kind of simplification of problems, a characteristic from which their operational nature derives. Such simplification may have a negative effect on a broader understanding of the issues or problems, and may even bias the respective academic research. Rather than depoliticization of government decisions, what would have been is a politicization and degradation of a considerable segment of research activities.

The economic and social issues are so dynamic and related and the government activities that affect them are so numerous and interconnected that the precision in the interpretation of the developments or in the prediction of the results of any new intervention seems doubtful. In any case, it is also necessary to consider the danger of ideologizing the issues on the public agenda, or their analysis in contexts that are not specific or impossible to convert into real policies. 
The concept of public policies includes both government and state issues. The latter are, in reality, policies of more than one government, which raises a political specificity. It is also possible to consider as state policies those that involve the set of state powers in their design or execution.

\subsection{Educational Policies in Chile (This May be One of Its Management)}

In the period from 2004 to 2016, important changes have been observed in educational policies in Chile. However, even though important achievements have been made, today education remains the main challenge facing the country to become a more egalitarian and truly developed society.

Despite the efforts, the educational system in Chile presents high levels of segregation and inequality that were installed due to certain practices such as shared financing and school selection. The existence of a copayment discriminates against families based on their economic capacity, and contributes to increasing segregation in the country without significantly contributing to quality (Mizala \& Torche, 2012; Bellei, 2013; Elacqua et al., 2013). Consequently, families do not have the possibility to choose the establishment they want their children to attend, but can only choose those that have the possibility of paying.

In addition, before the implementation of the School Inclusion Law, nearly $80 \%$ of the schools and lyceums that received a state subsidy required parents to meet some entry requirement to the establishment (Presidency of the Republic, 2014). School selection deepens segregation, by encouraging and allowing establishments to choose their students according to the social, economic and cultural capital of families. At the same time and similar to what happens with shared financing, selection does not guarantee greater educational effectiveness (Carrasco et al., 2014). Politics as finally, is then a result of confrontations and commitments, of competitions and coalitions of conflicts and convenient transactions of the Government in power.

In Chile, the economic globalization policy developed from the 1990s was characterized by economic openness and its reorientation towards the external market. But, the important technological modernization and adjustment policies that ended up producing the increase in unemployment and the reduction of public spending on social coverage. Public policies were interpreted only to the action of the social sectors, biasing the State's capacity to respond to the effects caused by economic policies and reducing its action to emergency situations. The social policies derived from these public policies were characterized by allocating a high budgetary cost for their implementation and ineffective results to solve the problems derived from poverty.

So much so, that 1 os social programs became a social control mechanism, through which more powerful actors have a strong influence to legitimize the perspectives and ideologies in areas of poverty. Focused in this way, the field of social assistance ends up producing a bureaucratization of public policies and a markedly fragmented profile characterized by the disarticulation of actions, the lack of competitiveness and inequity in the distribution of resources.

The economic evolution of Chilean capitalism has produced a contrast between misery and wealth, strengthening these inequalities. The spread of poverty has generated some worrisome social problems such as malnutrition, disease and ignorance. The impact of poverty and its innumerable consequences are as devastating as the uncertainty of what is to come. Its increase is the consequence of the social costs implemented by the accompanying policy model, whose new accumulation patterns extended the unequal distribution of income.

Economic policy is revealed because it is not possible to analyze social policy without relating it to economic development, and vice versa. The phenomenon of increasing poverty produced a decrease in the standard of living of certain population groups, marking strong social differences. But this increase is not new and its increase does not stop.

\section{What Do We Understand by Government and Public Policies?}

The limits, times and techniques that separated the activities of the government and those corresponding to political campaigns have become more blurred. The campaigns seek to persuade and the government to make, but this distinction is more or less sharp, according to the political system of each country and the majority that the government has in parliament. The deadlines in the campaigns are indefinite, everything seems possible at any minute. Not so in government, where options and sequences are very important.

As a result, the time of politics seems to have become permanent which often results in a discredit of the activity. Political campaigns aim to obtain votes or approval percentages in surveys, an objective shared by governments. On the other hand, campaigns do not require being precise or detailed, but based on simplifying phrases.

The campaigns are based on the use of surveys as a proxy for less spaced votes; and in communications based on one sentence per day, pseudo events and the privilege of television images. The government will usually have more 
material with which to approach the public and will have achievements to show, while the parties remain in limbo until the next elections. This trend may contribute to the decline of political parties.

The existence of the "paradox of determination" has been raised, according to which the great conditions of political-economic balance, whatever they may be, predetermine what will happen. However, a mistake is made when public policies are advised based on a narrow view of their feasibility. There is no essential difference between technical, economic, political, institutional or any other restrictions: they all limit the ruler's freedom of choice, and their violation always carries a sanction.

Governments must specify public policy programs for their period. This determination is an effective way of not giving many people what they want. Typically, there are no optimal public policies, but rather a range of possible solutions. There is no guarantee of choosing the best public policy. But it is a duty of governments to choose courses of action.

It is convenient to distinguish between the public program and the government's agenda, sometimes because demagoguery inflated the program and, in any case, because it aspires to choose optimal sequences, waterfall effects, political and economic moments. A central activity of an interest group is managing to incorporate their own alternatives to agenda items that others have made prominent. This affects the policies considered, even if the respective agenda is not affected.

Governments need to coordinate their public policies with political parties. Political parties must be able to organize for the elections, but also to govern; For this, it would be convenient to strengthen the study institutes linked to them and insist on the incorporation of people with technical and scientific capacity to design public policy proposals.

Some public policies are more important than others. And it is in the nature of good governance that its action is mainly organized around strategic guidelines and policies. Strategic policies are those that prefigure the government's legacy. They must give the main criteria for evaluating their own management and allow the parties that support the government to be ordered.

A medium-term strategic vision is required that adequately combines the political and technical dimensions of public policy. For this, it is convenient to institutionalize a "road map" for government management, which is periodically evaluated and updated. The prospective analysis function should become a formal routine in the management of the Executive Branch.

Now, g erning is an affirmation of the will, an attempt to exercise control, to shape the world. While public policies are instruments of this determined ambition.

There is an agreement that public policies are important, but the usual concept of them is imprecise and the poor quality of policies is a general phenomenon. The challenge is to define the first and improve the second.

Public policies establish courses of action to address problems or to provide goods and services to segments of society. Policies do more than simply announce a course of action.

It is a reality that the role of the Chilean government and companies have undergone major structural transformations that have changed the landscape of the economy and politics during the last decades that make the implementation of new policies necessary. However, these transformations have fragmented society in such a way that the economic, cultural and social empowerment and development of the communities is uneven.

We must go beyond questioning what is the correct public policy to resolve this great debate clarify and what makes public policy work.

- Governments, by taking constitutional and political responsibility for many of the social and economic problems that affect individuals and social groups, have tended to shift the emphasis from "politics" to the axis of "public policy".

- Such problems demanded a solution by governments, it was necessary to ensure social welfare. It is in this context that public policies regain importance. Ultimately, "politics", it has been argued, consists of determining who gets what, when and how, based on public policies. However, it would be a mistake to assume that "politics" is the same as "public policy" since these are very different issues.

- Politics is a concept, unlike public policies, more related to the issue of power (and its legitimate use) in society. And public policies, for their part, are an instrument of the current government, of public affairs, education and the resolution of problems felt in a society, in all areas.

However; you can have the policy: Satisfaction of the educational needs of the youth sectors of school age with a high degree of vulnerability". For said public policy, programs that support the development of these can be generated, but today the lack of fiscal resources prevents the development of educational projects of the government in power, 
contradictory investment in education in the last decade has been increasing, which it is reflected in the educational quality of the country.

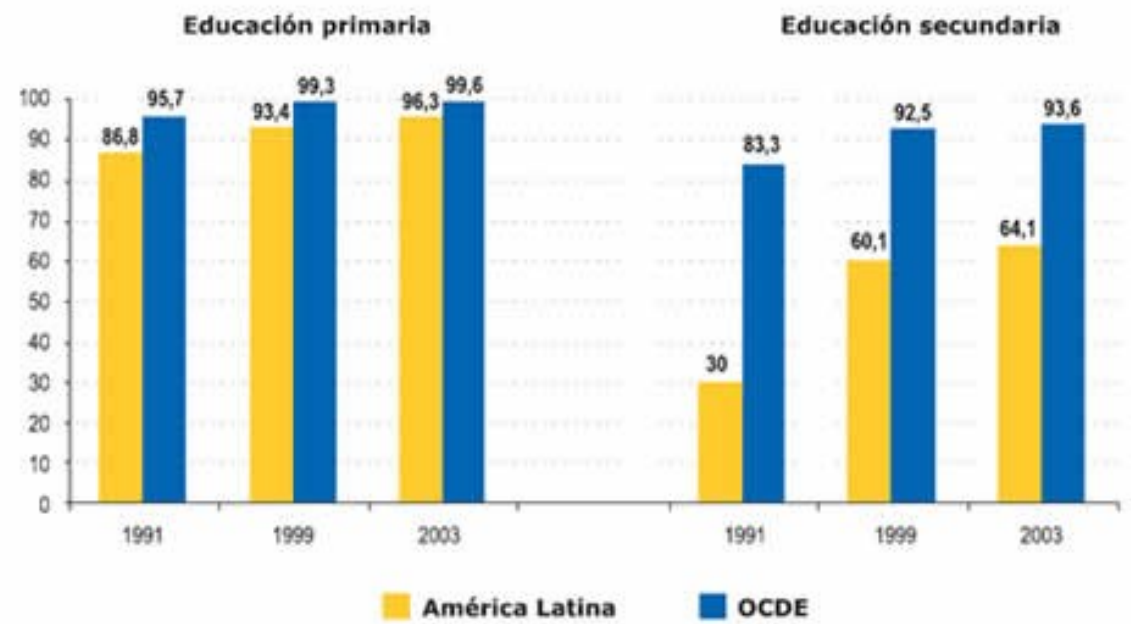

Figure 1. Students' Teaching Level

Source: National Education Policy Assessments. OECD

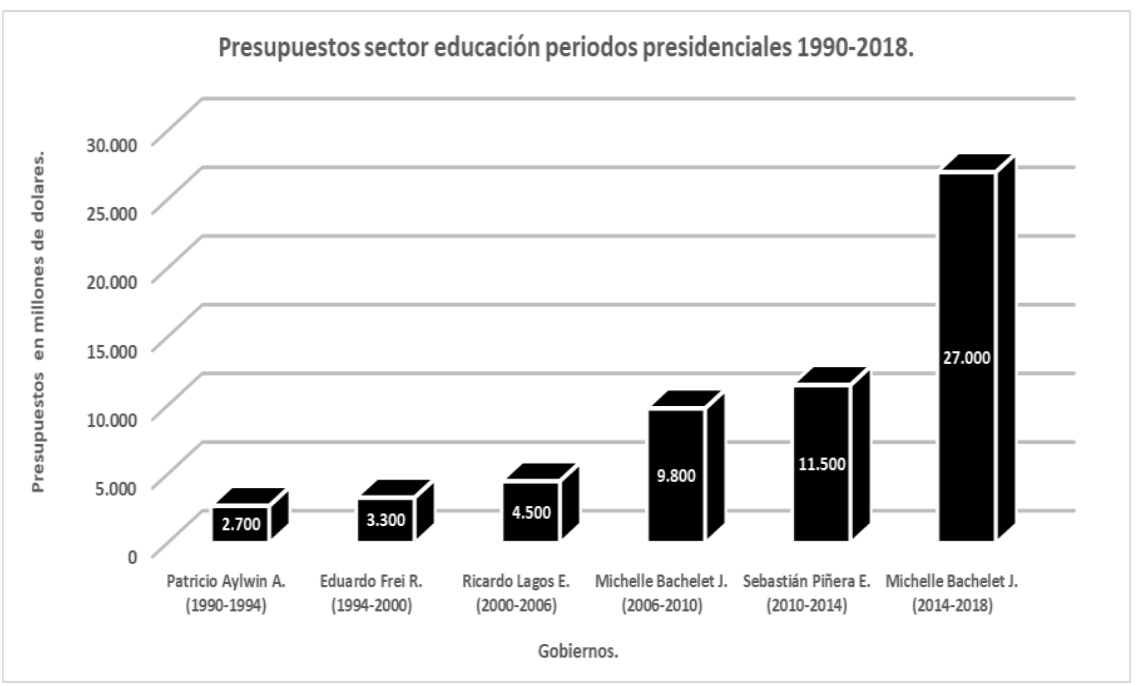

Figure 2. Budgets Education Sector Presidential Periods 1990 -2018

Source: Own Elaboration with Data from Centro de Estudios Mineduc, 2017

It could be said that the history of educational policies in Chile dates back to 1810, with the starting plan for public education. Since then, several milestones stand out, among them the approval of the Organic Law of Primary Instruction in 1860 and the Law of Compulsory Primary Education in 1920.

During the governments of Eduardo Frei Montalva and Salvador Allende, reforms in the educational field took priority and deserve to be highlighted. For example, the advance of 6 to 8 years in the basic education cycle, and to 4 years in the case of secondary education. During this period, there was also a great expansion of educational coverage and opportunities (Oliva, 2010). Already, the most contemporary phase in the history of educational policies in Chile can, in turn, be divided into two periods of analysis: the military dictatorship and governments in democracy.

In the first case, during the 1980s, a profound educational reform began, under a logic of competition, as summarized in figure 1 below. On the one hand, the administration of public school establishments was transferred from the central 
level to the country's municipalities. On the other, a demand financing system was introduced through a monthly voucher per student attending the school. The figure of the "educational holder" was created, who assumes, before the State, the responsibility of managing a school or high school according to the subsidies law (García-Huidobro, 2007).

1980
DFL 1-3063, de 1980 (13/06): Municipalización.
Constitución de 1980 (08/08): Consagra la libertad
de enseñanza.
DL 3476 (29/08) y DS 8144 (25/09), de 1980:
Financiamiento vía voucher.
Ley 18.768, de 1988: Creación del financiamiento
compartido.
Creación del SIMCE, 1988.
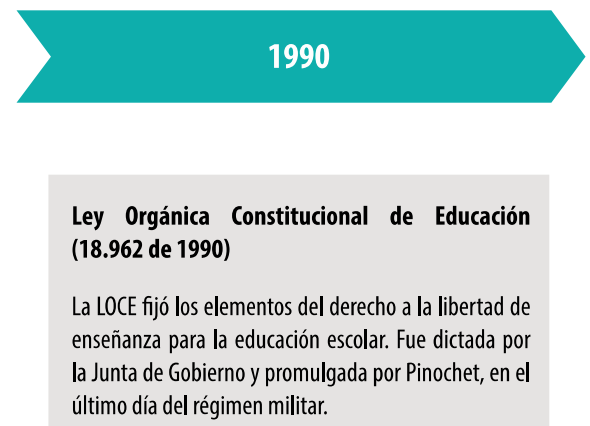

La LOCE fijó los elementos del derecho a la libertad de enseñanza para la educación escolar. Fue dictada por la Junta de Gobierno y promulgada por Pinochet, en el último día del régimen militar.

Gráfica 1 - Principales cambios legales durante el régimen militar Fuente: Elaboración propia.

Figure 3. Main Legal Changes during the Military Regime

- Since 1990, with the return of democracy, the theme of education has evolved from a coverage and scope approach in the 90s towards policies focused on quality assurance, equity and inclusion. These last aspects have been promoted especially since 2006, with the student marches and the involvement of society in general.

- As of that date, a period of participation of key actors has begun in the elaboration of policies, which has influenced several fundamental laws that provide the basis for a structural reform of the Chilean educational system, such as the Preferential School Grant (SEP), the General Education Law (LGE), the Quality Assurance Law (SAC), the Inclusion Law, the Teaching Career Law and the Law that creates the new Public Education System. The Figure 4 below summarizes the most important milestones to date.

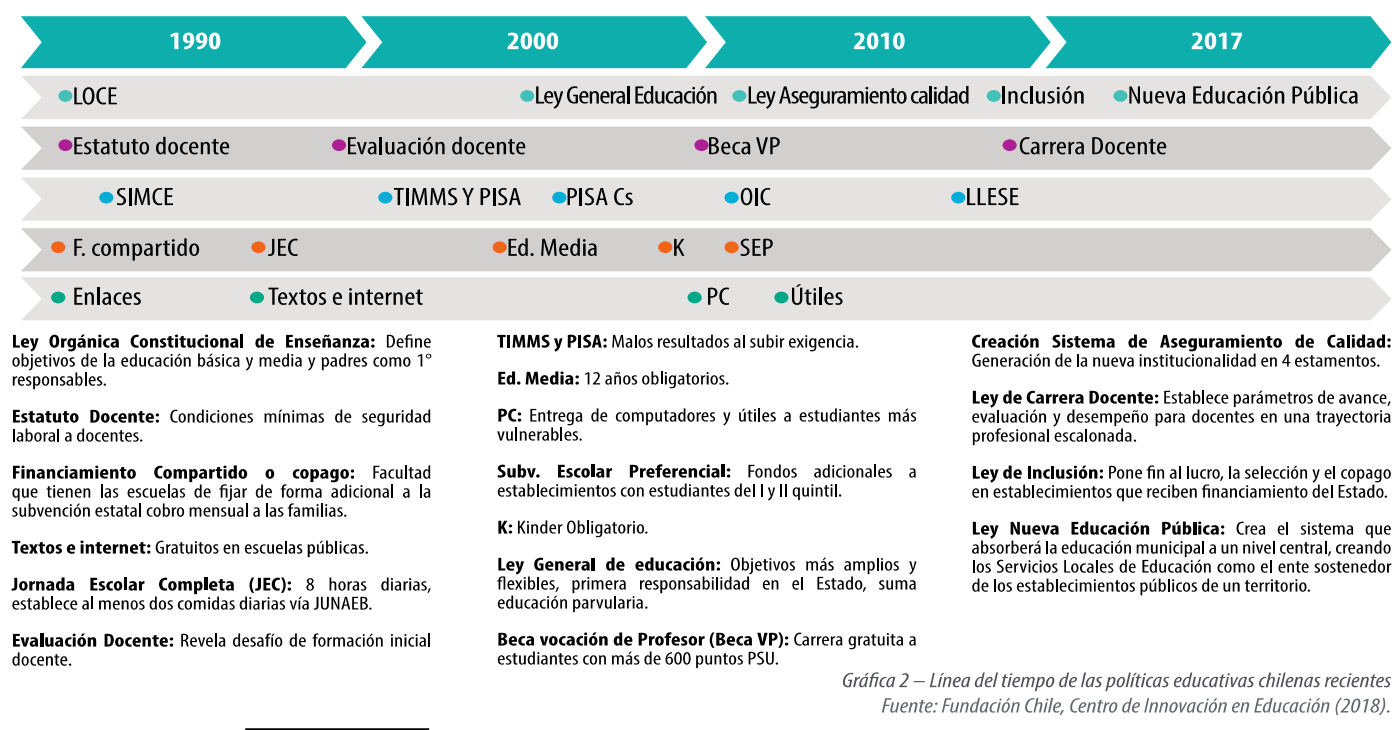

Figure 4. The Most Important Milestones to Date

- After the last 40 years of reforms, a regulatory framework and a set of educational policies have been installed that emphasize different principles and follow motivations that are often antagonistic: from competition to collaboration, from selection to inclusion, and from imposition external support for internal capacity building. 
- Although this inconsistency of the system should decrease with the reforms of the last government -with the inclusion law-, the implementation of those reforms is a key point. Likewise, the interaction of these laws with demand financing and a highly demanding external responsibility system is certainly a challenge that remains.

How school actors interpret and implement these educational policies and their demands is an issue to be studied in depth in Chile. Regarding the contradictions in policies, Acuña et al. (2014) emphasizes, for example, that educational inclusion, as a principle and a right, is both stimulated and hindered by the system, given the differences in incentives from the financing system on the one hand, and responsibility on the other.

In many ways, therefore, a tension is perceived that is mainly due to the lack of coherence of the system and its educational policies, and to the overlapping of contradictory schemes of pressure and support for school actors.

As Munby and Fullan (2016) point out, this type of struggle between discourses and policies at the national level on one sidewalk, and the actions or omissions of schools, on the opposite sidewalk, results in a type of friction that in a certain way The mode produces heat but does not give light, since its results, or the levers it moves, are not sufficient to produce a systemic change.

This, according to Munby and Fullan (2016), implies a great challenge and at the same time a great opportunity for intermediate leaders, who on the one hand,

"They can remain victims of a fragmented system with top-down policies or they can work for change. The idea is not to be a rebel without a cause, but to change the game of obeying, to be focused with a sense. It is the responsibility of leaders to model a culture that ensures that although they take into account the requirements of external accountability at the national level, they develop internal accountability that leads to expected results. Media leaders need to consider ambitious alternatives that build capacity at the heart of systems" (p. 13).

On the other hand, for several years, the idea has been questioned by different means that governing by public policies varies in the short-term expectations compared to the long-term consequences, since they often tend to have unexpected results, they function as a type of experimentation based on "trial and error" reflection and debate on the $\mathrm{c}$ ONSTITUTION Chile has lost relevance today, as a result of the social upheaval of the country.

Consequently, addressing the problem with the wrong tools can be worse than not addressing the problem, as citizens must be guaranteed fair access to public policies that can only be granted by improving the country's governance.

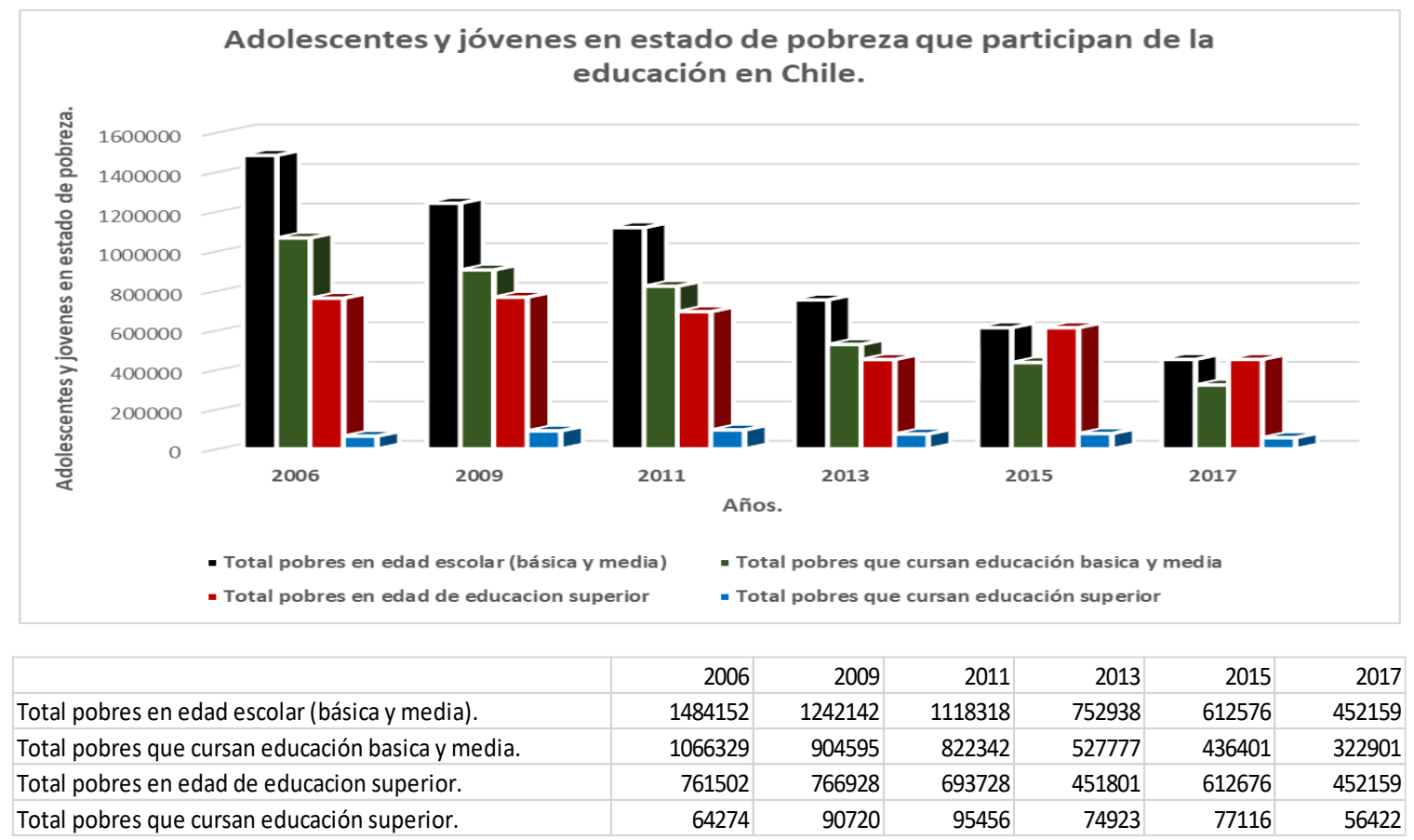

Figure 5. Adolescents and Youths in Poverty Who Participate in Chilean Education

Source: Own Elaboration with Data from the CASEN Survey Period 2006-2017 
Therefore, although public policies are actions merely the government, it is not limited to this, 1 will citizens are responsible also to generate a significant change, because as said Paul Romer (2019), Chief Economist of the World Bank "officials The government does not act in a vacuum. Their decisions reflect the bargaining power of citizens who compete with each other to defend competing interests, " and focusing as citizens on governance, as a key response to the challenges facing Chile today, will be the future guarantee for compliance. of the law in the interest of equity, development and prosperity.

In short, public policies participate in national development by solving and responding to the various deficiencies, needs, interests, demands and individual and community predilections, in order to make possible the progress of citizens and reinforce their coexistence.

They must be established within the current legal framework, be prepared by people trained to do so, have financial viability, be oriented towards the common good and allow citizen participation.

Public policy evaluations must be impartial, they are made for improvement, not for stigmatization, as a follow-up and monitoring action; They must include any moment, from the definition of priorities and elaboration of the design, implementation, resources, performance during its course, partial results, complications and difficulties, to final results and incidence on users.

The evaluations of the national policies carried out present relevant elements for decision-making in the context of the important transformations and processes of educational reform that Chile is experiencing. It analyzes the educational continuum and highlights recommendations that, if implemented, could have positive impacts on the quality of learning and the equity of the system as a whole. The p public olicy in Chile must be designed and managed learning environments that advance quality to be drivers of creativity, innovation and inclusion.

\section{Conclusions}

By finally, the role of political public in educational improvement depends on the context of each establishment, ie those external elements that influence the daily life of each school community (Spillane et to the. 2002). The external element considered most explanatory of the educational results is the socioeconomic level in which the educational establishments are immersed. Another very important element, which influences the way in which a school responds to policies and projects improvement, is that linked to institutional pressure or support from intermediate authorities (Trujillo, 2013; Woulfin et al. 2016). Although, indeed, the school, through its internal capabilities, is the main unit of change, leadership holder is key in terms of how the policies are perceived or received by a school, which influence the appropriate (or not) implementation thereof, both because of (or lack of) support technical and pedagogical as political and economic (Spillane, 1996; Leithwood et al., 2004; Trujillo, 2013; Woulfin et al., 2016; Valenzuela Montecinos, 2017).

From the foregoing, it is clarified that Public Policies are the consequence of:

- Guideline, decision guideline that defines how to act in special cases.

- The public nature of the policies is given by the participation of the different actors involved in these decisions.

- Set of decisions, principles and norms that guide action, defining concrete objectives and goals aimed at legitimizing and exercising the power and authority that lead to satisfying certain needs of a country, sector, institution, community.

- Once we have already analyzed and conceptualized Public Policies, which we can say, from a civil society perspective, Public Policies are relevant, since they constitute one of the socially available instruments to meet the needs of the population. The vision that needs to be emphasized here is, one of an instrumental type emphasizing that they are "means to", the resolution of social problems. From the above it can be deduced that the ideal of a government is to have state policies, to maintain them over time, oblivious to the current government.

\section{References}

Arellano, J. P (2001). The educational reform in Chile: achievements, projects and stagnations. CEPAL Review, 73, 83-94. https://doi.org/10.18356/706e2026-es

Bellei, C., Contreras, D., \& Valenzuela, J. (2008). The pending agenda in education. Santiago: UNICEF.

Bellei, C. (2013). Economic and academic segregation of Chilean education: magnitude, causes and consequences. Pedagogical studies, 325-345. 
Carrasco, A., Gutiérrez, G., Bogolasky , F., Rivero, R., \& Zahri , M. (2014). Analysis on the design and implementation of the end of the school selection in the context of the educational reform in Chile, Summary of the thesis to apply for the degree of master's in management and Public Policies, Santiago, Chile.

CEPAL (1996). Fiscal Decentralization in Latin America. Notes on the economy and development $N^{o r}$ 596, Santiago, Chile, October.

Education Quality Agency (2004). Simce Results 2004 4th basic by establishment. Retrieved from $\mathrm{http}: / /$ www.Agenciaeducacion.cl/simce /national-databases-/Chile

Educational Quality Agency (2006). Simce Results 2006 2nd average per establishment. Retrieved from $\mathrm{http}: / / \mathrm{www}$. Agenciaeducacion.cl/ simce/national-databases-/Chile

Educational Quality Agency (2012). Simce Results 2012 4th basic by establishment. Retrieved from $\mathrm{http}: / /$ www.Agenciaeducacion.cl/simce /national-databases-/Chile

Public Policy Center of the Pontificia Universidad Católica de Chile (2014). Study on the technical-pedagogical assistance model of the Chilean Ministry of Education to subsidized educational establishments in the country. Chile.

Martínez, J. (2016). Internet and Socially Relevant Public Policies, why, how and what to influence, 509-541, Costa Rica.

Rodríguez, J. (2017). Public Policies. RVE, 4(2), 17-26.

Spillane-J-P. (2002). Retrieved from Local-theories-of-teacher-change-the-pedagogy-of-district-policies-and programs-teacher-college-record-104-377-420

\section{Copyrights}

Copyright for this article is retained by the author(s), with first publication rights granted to the journal.

This is an open-access article distributed under the terms and conditions of the Creative Commons Attribution license (http://creativecommons.org/licenses/by/4.0/). 